\title{
Keefektifan Model Pembelajaran Quantum Teaching Terhadap Keaktifan dan Prestasi Belajar Siswa Pada Mata Pelajaran IPS
}

\author{
Dinar Ayu Wening Palupi ${ }^{1 *}$, M.Yusuf Setia $W^{2}$, Diana Endah Handayani ${ }^{3}$
}

${ }^{123}$ Program Studi Pendidikan Guru Sekolah Dasar, Fakultas ILmu Pendidikan, Universitas PGRI Semarang

\begin{tabular}{l} 
A R T I C L E I N F O \\
\hline Article history: \\
Received 18 August 2019 \\
Received in revised form \\
19 September 2019 \\
Accepted 25 October 2019 \\
Available online 30 \\
November 2019 \\
\hline Kata Kunci: \\
Model Pembelajaran \\
Quantum Teaching, \\
Keaktifan Belajar, Prestasi \\
Belajar \\
Keywords: \\
Quantum Teaching Learning \\
Model, Learning Activity, \\
Learning Achievement
\end{tabular}

\section{ARTICLEINFO}

Received 18 August 2019

Available online 30

Kata Kunci:

Model Pembelajaran

Quantum Teaching,

Keaktifan Belajar, Prestasi

Keywords:

Model, Learning Activity,

Learning Achievement

\begin{abstract}
A B S T R A K
Tujuan yang hendaknya dicapai dalam penelitian ini adalah untuk mengidentifikasi efektif atau tidaknya model pembelajaran Quantum Teaching terhadap prestasi dan keaktifan belajar siswa pada mata pelajaran IPS kelas V SDN 3 Bedagas dilihat pada ketuntasan belajar dan hasil belajar. Jenis penelitian ini adalah penelitian kuantitatif dalam bentuk desain non equivalent (pretest and posttest)control group design. Populasi penelitian ini adalah seluruh peserta didik kelas V SDN 3 Bedagas Purbalingga. Sampel yang diambil adalah 35 peserta didik kelas 5 yang terdiri dari kelas VA berjumlah 17 peserta didik dan kelas VB yang berjumlah 18 peserta didik dengan menggunakan teknik nonprobability sampling dengan sampling jenuh. Data dalam penelitian ini diperoleh melalui observasi, wawancara, tes dan dokumentasi. Setelah diberikan perlakuan dengan menggunakan model pembelajaran Quantum Teaching nilai rata-rata prestasi belajar siswa kelas eksperimen meningkat sebanyak 14,72. Rata-rata keaktifan belajar kelas kontrol sebelum perlakuan sebesar 64 sedangkan untuk kelas eksperimen sebesar 63 dan nilai rata-rata keaktifan belajar siswa kelas kontrol sesudah perlakuan sebesar 70 sedangkan kelas eksperimen sebesar 75,5 dan kedua kelas tersebut dapat dikategorikan dalam tingkat keaktifan belajar siswa yang baik. Oleh karena itu dapat disimpulkan bahwa model pembelajaran Quantum Teaching efektif terhadap keaktifan dan prestasi belajar siswa kelas $\mathrm{V}$ di SDN 3 Bedagas.
\end{abstract}

\section{A B S T R A C T}

The objective that should be achieved in this study is to identify whether or not the Quantum Teaching learning model is effective or not on the achievement and learning activeness of students in social studies subject class V SDN 3 Bedagas seen in mastery learning and learning outcomes. This type of research is quantitative research in the form of non equivalent design (pretest and posttest) control group design. The research population was all students of class V SDN 3 Bedagas Purbalingga. Samples taken were 35 class 5 students consisting of VA class totaling 17 students and class VB totaling 18 students using nonprobability sampling techniques with saturated sampling. The data in this study were obtained through observation, interviews, tests and documentation. After being given treatment using the Quantum Teaching learning model the average value of student achievement in the experimental class increased by 14.72. The average learning activeness of the control class before treatment is 64 while for the experimental class is 63 and the average value of the learning activeness of the control class after treatment is 70 while the experimental class is 75.5 and both classes can be categorized in the level of student learning activeness well. Therefore it can be concluded that the Quantum Teaching learning model is effective against the activeness and learning achievement of fifth grade students at SDN 3 Bedagas. 


\section{Pendahuluan}

Pendidikan adalah upaya untuk memanusiakan manusia atau membentuk manusia menjadi manusia seutuhnya. Dikatakan demikian karena dengan pendidikan, manusia dapat dibentuk untuk lebih sempurna dari mahluk Tuhan yang lainnya sebagai khalifah di muka bumi ini. Menurut Undang-Undang No.20 Tahun 2003 tentang Sistem Pendidikan Nasional secara tegas menyebutkan bahwa pendidikan adalah usaha sadar dan terencana untuk mewujudkan suasana belajar dan proses pembelajaran agar peserta didik secara aktif mengembangkan potensi dirinya untuk memiliki potensi dirinya untuk memiliki kekuatan spiritual keagamaan, pengendalian diri, kepribadian kecerdasan, akhlak mulia, dan ketrampilan yang di perlukan oleh dirinya, masyarakat, dan negara. Peraturan Menteri Pendidikan Nasional Nomor 22 Tahun 2006 mengenai standar ini menyatakan bahwa Ilmu Pengetahuan Sosial (IPS) merupakan salah satu mata pelajaran yang diberikan mulai dari SD/MI/SDLB sampai SMP/MTs/SMPLB. IPS mengkaji seperangkat peristiwa , fakta, konsep, dan generalisasi yang berkaitan dengan isu sosial. Tujuan dati IPS sendiri antara lain (1) Mengenal konsep-konsep yang berkaitan dengan kehidupan masyarakat dan lingkungannya. (2) Memiliki kemampuan dasar untuk berfikir logis dan kritis, rasa ingin tahu, inquiri memecahkan masalah, dan ketrampilan dalam kehidupan sosial. (3) Memiliki komitmen dan kesadaran terhadap nilai-nilai sosial dan kemanusiaan. (4) memiliki kemampuan berkomunikasi, bekerjasama, dan berkompetensi dalam masyarakat yang majemuk, di tingkat local, nasional, dan global (Depdiknas, 2006: 575).

Mata pelajaran IPS disusun secara sistematis, komprehensif, dan terpadu dalam proses pembelajaran menuju kedewasaan dan keberhasilan dalam kehidupan di masyarakat, dengan pendekatan tersebut diharapkan siswa akan memperoleh pemahaman yang lebih luas dan mendalam pada bidang ilmu yang berkaitan.

Selama ini pembelajaran Ilmu Pengetahuan Sosial di sekolah yang dijalankan oleh guru hanya berpusat pada buku dan lembar soal.Fokus yang terjadi dalam pembelajaran di kelas masih berfokus terhadap guru sedangkan siswa kurang mempunyai partisipasi aktif dalam pembelajaran yang berlangsung. Siswa hanya menunggu guru memberi perintah, jika tidak maka yang dilakukan siswa hanya diam. Pembelajaran yang demikian akan menghambat kreatifitas peserta didik serta hak untuk mengeluarkan pendapat yang akan berakibat pada rendahnya prestasi yang diperoleh peserta didik. Guru sebagai pendidik haruslah memiliki kiat-kiat inovatif dan kreatif untuk menciptakan suasana pembelajaran yang baik dan kondusif dalam hal ini adalah dalampelajaran lmu Pengetahuan Sosial.

Dalam pembelajaran siswa pada umumnya hanya menghafal konsep dan kurang mampu menggunakan konsep tersebut jika menemui masalah dalam kehidupan nyata yang berhubungan dengan konsep yang dimiliki.Hal ini membuktikan bahwa kemampuan siswa dalam memecahkan masalah masih tergolong rendah. Ini terlihat saat guru memberikan suatu masalah atau pertanyaan yang harus diselesaikan siswa dengan cara penyelesaian, siswa cenderung menjawabnya secara langsung tanpa melalui suatu tahap-tahap atau cara-cara penyelesaiannya bahkan ada yang tidak menjawabnya karena kurangnya pemahaman siswa terhadap permasalahan tersebut.Hal ini diakibatkan karena model pembelajaran yang sering digunakan guru adalah model pembelajaran konvensional seperti ceramah, yang hanya berpusat pada guru.Siswa disini hanya mendengarkan penjelasan dari guru dan mencatat halhal penting yang perlu dicatat. Melalui model ini siswa mendapatkan banyak pengetahuan dari guru, akan tetapi siswa hanya menerimanya begitu saja tanpa mengetahui asal-usul atau sejarahnya. Sehingga pembelajaran yang terjadi menjadi kurang efektif dan bermakna.

Pembelajaran yang kurang efektif dan kurang mengaktifkan siswa dalam proses pembelajaran akan menghambat proses belajar siswa, khususnya kemampuan siswa dalam memecahkan masalah. Untuk itu guru perlu menerapkan suatu model pembelajaran yang dapat mengaktifkan siswa dalam belajar dan dapat meningkatkan kemampuan siswa dalam memecahkan masalah.Sehingga peran guru nantinya hanya sebagai fasilitator dan motivator.Ketika siswa belajar tentang materi yang akan dipelajari nanti, maka tugas guru adalah bagaimana menerapkan materi ini agar dekat dengan kehidupan siswa sehari-hari.Guru harus dapat memberikan contoh serta permasalahan yang berkaitan dengan kehidupan siswa seharihari.Namun pada kenyataannya guru tidak pernah menanamkan konsep pembelajaran yang dapat memperlihatkan secara nyata permasalahan kepada siswa.Sehingga pemahaman siswa mengenai materi yang akan diajarkan ini belum tumbuh.

Berdasarkan wawancara dengan ibu Jartiyah selaku wali kelas VB, kesulitan guru dalam proses pembelajaran yaitu karena siswa masih senang berbicara sendiri dan bermain. Sedangkan pada proses pembelajaran, IPS hanya sebagai mata pelajaran hafalan. Pada saat proses pembelajaran guru hanya memberikan teori saja dan memfokuskan kepada buku pegangan dan pencapaian materi berupa teori. Sehingga hasil belajar yang diperoleh siswa rendah, mata pelajaran IPS merupakan mata pelajaran yang berguna bagi siswa guna memahami diri dan lingkungan, membuat hidupnya menjadi lebih "kaya" dan 
menyenangkan dan memberikan kegunaan bagi dirinya (Wahab, 2009:30). Pada proses pembelajaran di kelas guru masih menggunakan metode pembelajaran konvensional, hal ini mengakibatkan siswa kurang aktif dan mendapatkan nilai yang kurang maksimal. Padahal yang sudah dikemukakan di atas tersebut bahwa mata pelajaran menyangkut dirinya sendiri dan lingkungan, yang hendaknya siswa harus mengeksplor dirinya atau apa yang di terimanya (pemrosesan informasi) dan berinteraksi dengan lingkungan sekitar.

Dari fakta yang ada bahwa hasil belajar UTS siswa kelas V SDN 02 Bedagas rendah dengan batas KKM mata pelajaran IPS adalah 70. Dari 17 siswa kelas VA terdapat 55\% siswa mendapat nilai dibawah KKM dengan nilai terendah 38 dan dari 18 siswa kelas VB terdapat 52\% siswa mendapat nilai dibawah KKM dengan nilai terendah 51. Dalam penelitian ini peneliti memperkenalkan model pembelajran yang menyenangka untuk digunakan dalam materi pentingnya menghargai jasa dan peranan tokoh dalam mempersiapkan kemerdekaan Indonesia serta sebagai generasi penerus bangsa hendaknya dapat menyikapi perjuangan para pahlawan tersebut.

Untuk mengatasi permasalahan yang terjadi diperlukan upaya agar siswa aktif dalam pembelajaran. Salah satu alternatif yang dilakukan adalah menggunakan model Quantum Teaching. Penelitian terdahulu yang relevan yaitu Gagas Punjung (2017) dalam skripsinya yang berjudul "Pengaruh Model Pembelajran Quantum Teaching Terhadap Keaktifan dan Prestasi Belajar Siswa Pada Mata Pelajaran IPS Kelas V Sekolah Dasar". Peningkatan rata-rata prestasi belajar kelas kontrol sebelum diberikan perlakuan sebesar 68,62 dan sesudah diperlakuan sebesar 76,20 sedangkan untuk kelas eksperimen sebelum diberikan perlakuan sebesar 68,44 dan sesudah diberikan perlakuan sebesar 83,96 yang artinya rata-rata prestasi belajar mengalami peningkatan. Pada peningkatan rata-rata kaktifan siswa kelas kontrol sebelum perlakuan sebesar 43,27 setelah diperlakuan sebesar 46,68 sedangkan untuk keaktifan kelas eksperimen sebelum mendapatkan perlakuan sebesar 54,34 dan setelah diberikan perlakuan sebesar 58,86 yang artinya rata-rata keaktifan siswa mengalami peningkatan. Dapat disimpulkan bahwa ada pengaruh yang signifikan antara penggunaan model Quantum Teaching pada mata pelajaran IPS terhadap keaktifan dan prestasi belajar siswa kelas V Sekolah Dasar.

Quantum adalah interaksi yang mengubah energi menjadi cahaya. Quantum berasal dari bahasa inggris dapat diterjemahkan menjadi berdaya guna lebih.Teaching adalah pengajaran, jadi Quantum Teaching adalah pengajaran yang berdaya guna lebih dengan dengan orkestrasi bermacam-macam interaksi yang ada di dalam dan disekitar momen belajar.Asas utama pembelajaran Quantum Teaching menurut Depoter (2010:34) bersandar pada konsep: "Bawalah Dunia Mereka ke Dunia Kita, dan Antarkan Dunia kita ke Dunia Mereka."

Quantum teaching adalah suatu model pembelajaran yang memadukan seni dan pencapaian tujuan terarah melalui interaksi kelas yang dinamis. A'la (2010), mengemukakan " quantum teaching shows teacher how to orchestrate their students success by taking into account everything in the classroom along with the environment, the design of the curriculum, and how it's presented. The result: a highly effective way to teach anything to anybody". Bobbi DePorter seorang guru asal Amerika Serikat mengemukakan bahwa Quantum yaitu interaksi yang mengubah energy menjadi cahaya. Jadi quantum teaching merupakan pengubahan bermacam-macam interaksi yang ada di dalam dan disekitar momen belajar. Interaksi-interaksi ini mencakup unsure-unsur untuk belajar efektif yang mempengaruhi kesuksesan siswa dan mengubah kemampuan serta bakat ilmiah siswa menjadi cahaya yang akan bermanfaat bagi diri mereka dan orang lain (DePorter, dkk (2012). Demikian pula yang dikemukakan oleh A'la (2010), bahwa quantum teaching merupakan orkestrasi bermacam-macam interaksi yang ada di dalam dan disekitar momen belajar. Interaksi-interaksi itu mencakup unsure-unsur untuk belajar efektif yang mempengaruhi kesuksesan siswa secara menyeluruh. Interaksi-interaksi ini mengubah kemampuan dan bakat alamiah siswa menjadi cahaya yang akan bermanfaat bagi mereka sendiri dan orang lain sehingga proses pelaksanaannya tidak hanya sendirian, semuanya menjadi sangat penting karena keberadaannya saling menopang antara satu dengan yang lainnya. Quantum teaching merupakan salah satu model yang dilukiskan mirip sebuah orchestra, dimana kita seolah sedang memimpin konser saat sedang berada di kelas, karena disitu membutuhkan pemahaman terhadap karakter murid yang berbedabeda. Sebagaimana alat music seperti biola dan suling yang masing-masing memiliki suara yang berbeda. Oleh karena itu quantum teaching mengajarkan supaya setiap karakter dapat memiliki peran dan keterlibatan aktif murid dalam kegiatan pembelajaran akan membawa kesuksesan dalam belajar (DePorter dkk, 2012). Quantum teaching adalah sebuah program yang mengizinkan pendidik untuk memahami perbedaan gaya belajar para siswa di dalam kelas. Tujuannya ialah untuk mengajari pendidik bagaimana orang belajar dan mengapa siswa bertindak dan bereaksi terhadap sesuatu sebagaimana yang telah terjadi selama ini. Quantum teaching menunjukkan kepada guru cara untuk mengarang kesuksesan siswa mereka dengan mencatat apa saja di dalam kelas yang berkaitan dengan lingkungan, desain kurikulum dan cara mempresentasikannya. Quantum teaching merupakan cara yang paling efektif dalam 
mengajar siapa saja karena quantum teaching menawarkan ide baru tentang bagaimana menciptakan lingkungan yang jauh lebih baik serta yang menjanjikan bagi pelajar dan mendukung mereka dalam proses pembelajaran agar tidak terjadi ketidakseimbangan (Yahya, 2017).

\section{Metode}

Jenis Penelitian ini menggunakan Non Equivalent (pretest and posttest) control group design. Design ini digambarkan sebagai berikut:

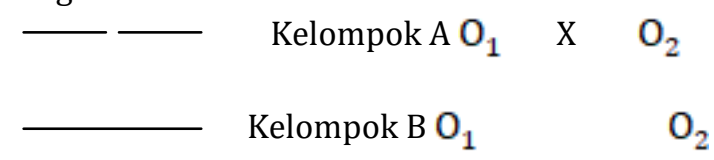

Gambar 1. Non Equivalent (pretest-Posttest) Control Group Design

Keterangan :

A = Kelompok eksperimen

$\mathrm{B}=$ Kelompok kontrol

$\mathrm{O}_{1}=$ Pretest

$\mathrm{O}_{2}=$ Postest

$\mathrm{X}=$ Perlakuan (menggunakan quantum teaching)

(Creswell, 2014:242)

Variabel penelitian ini yang digunakan ada dua yaitu variable independen (bebas) dan variabel dependen (terikat). Yang menjadi

\section{Hasil dan Pembahasan}

Ketuntasan Belajar Individu (KBI) dihitung dengan rumus berikut:

$$
K B I=\frac{\text { Jumlah skor diperoleh }}{\text { Jumlah skor maksimal }} \times 100 \%
$$

Siswa dinyatakan tuntas jika memiliki nilai sekurang-kurangnya 71 atau persentase KBI sebesar 70\%. Rekapitulasi ketuntasan belajar individu pada pretest dan posttest adalah sebagai berikut

Tabel 1. Rekapitulasi Ketuntasan Belajar Individu

\begin{tabular}{ccc}
\hline KBI & Tuntas & Tidak Tuntas \\
\hline Pretest kelas kontrol & $7(41,18 \%)$ & $10(58,82 \%)$ \\
Pretest kelas eksperimen & $7(38,89 \%)$ & $11(61,11 \%)$ \\
Posttest kelas kontrol & $11(64,71 \%)$ & $6(35,29 \%)$ \\
Posttest kelas eksperimen & $16(88,89 \%)$ & $2(10 \%)$ \\
\hline
\end{tabular}

Sumber: Data Hasil Penelitian 2019

Berdasarkan hasil perhitungan Ketuntasan Belajar Individu (KBI) dengan siswa sebanyak 35 pada pretest dan posttest. Pada hasil pretest kelas kontrol diperoleh hasil dengan jumlah 7 siswa yang tuntas dan pada posttest dengan jumlah 11 siswa yang tuntas, sedangkan untuk kelas eksperimen diperoleh hasil dengn jumlah 7 siswa yang tuntas dan pada posttest kelas eksperimen 16 siswa yang tuntas, hal ini menunjukkan Ketuntasan Belajar Individu sesudah diberikan perlakuan lebih besar dari Ketuntasan Belajar Individu sebelum diberikan perlakuan. Ketuntasan Belajar Kelompok (KBK) dihitung dengan menggunakan rumus berikut:

$$
K B K=\frac{\text { Jumlah siswa yang tuntas }}{\text { Jumlah siswa yang mengikuti tes }} \times 100 \%
$$

Ketuntasan belajar klasikal tercapai jika memiliki persentase sekurang-kurangnya adalah $70 \%$. Rekapitulasi ketuntasan belajar klasikal adalah sebagai berikut 
Tabel 2. Rekapitulasi Ketuntasan Belajar Klasikal

\begin{tabular}{|c|c|c|c|c|c|c|c|c|}
\hline & \multicolumn{4}{|c|}{ Pretest } & \multicolumn{4}{|c|}{ Posttest } \\
\hline & \multicolumn{2}{|c|}{ Jumlah siswa } & \multicolumn{2}{|c|}{ Presentase } & \multicolumn{2}{|c|}{ Jumlah siswa } & \multicolumn{2}{|c|}{ Presentase } \\
\hline & Kon & Ekspe & Kon & Ekspe & Kon & Ekspe & Kon & Ekspe \\
\hline & trol & rimen & trol & rimen & trol & rimen & Trol & Rimen \\
\hline Tuntas & 7 & 7 & $41,18 \%$ & $38,89 \%$ & 11 & 16 & $64,71 \%$ & $88,89 \%$ \\
\hline Tidak & 10 & 11 & $58,82 \%$ & $61,11 \%$ & 6 & 2 & $35,29 \%$ & $10 \%$ \\
\hline Tuntas & & & & & & & & \\
\hline
\end{tabular}

Sumber : Data Hasil Penelitian (2019)

Berdasarkan hasil perhitungan Ketuntasan Belajar Klasikal (KBK) dengan siswa sebanyak 35. Pada hasil pretest kelas kontrol dan kelas eksperimen diperoleh hasil dengan jumlah 7 siswa yang tuntas untuk kelas kontrol dan 7 siswa yang tuntas untuk kelas eksperimen, sehingga diperoleh persentase KBK pada pretest sebesar 41,18\% dan 38,89\% sehingga dinyatakan tidak tuntas atau ketuntasan klasikal belajar tidak tercapai dan Persentase KBK pada posttest kelas kontrol dengan jumlah siswa yang tuntas 11 dan kelas eksperimen 16 siswa, sehingga diperoleh persentase KBK untuk kelas control 64,71\% dan kelas eksperimen sebesar 88,89\% sehingga dapat dinyatakan bahwa Ketuntasan Belajar Klasikal kelas kontrol belum tercapai sedangkan kelas eksperimen tercapai. Terjadinya peningkatan pada saat sebelum dan sesudah diberikan pembelajaran dengan model pembelajaran Quantum Teaching ketuntasan belajar individu (KBI) dan ketuntasan belajar klasikal (KBK) dengan kriteria ketuntasan minimal (KKM) sebesar 71. Pada ketuntasan belajar individual pretest kelas kontrol diperoleh hasil bahwa sebanyak 7 siswa tuntas dan 10 siswa tidak tuntas dengan persentase KBK sebesar 41,18\% sedangkan pada ketuntasan belajar individual pretest kela eksperimen diperoleh hasil bahwa sebanyak 7 siswa tuntas dan 11 siswa tidak tuntas dengan presentase KBK sebesar 38,89\%. Pada posttest kelas kontrol diperoleh hasil siswa yang tuntas sebanyak 11 dan 6 siswa tidak tuntas dengan persentase KBK sebesar 64,71\% sedangkan untuk kelas eksperimen diperoleh hasil bahwa sebanyak 16 siswa yang tuntas dan 2 siswa yang tidak tuntas dengan presentase KBK 88,89\%. Hal ini menunjukkan bahwa pembelajaran dengan Model pembelajaran Quantum Teaching memberikan dampak pada ketuntasan belajar individual dan kelompok

Selama proses pembelajran keaktifan siswa diamatai menggunakan lembar pengamatan (lembar observasi) yang terdiri dari 5 indikator dan setiap indikator terdapat 4 deskriptor dengan kategori keaktifan sebagai berikut

Tabel 3. Kategori keaktifan siswa

\begin{tabular}{ccc}
\hline Presentase skor & Predikat & Keterangan \\
\hline $81 \%-100 \%$ & $\mathrm{~A}$ & Sangat Baik \\
$66 \%-80 \%$ & $\mathrm{~B}$ & Baik \\
$51 \%-65 \%$ & $\mathrm{C}$ & Cukup \\
$0 \%-50 \%$ & $\mathrm{D}$ & Kurang \\
\hline
\end{tabular}

Lembar pengamatan diisi oleh observer selama kegiatan pembelajaran berlangsung. Perhitungan nilai keaktifan sebelum perlakuan dan sesudah perlakuan hasilnya berbeda berikut adalah daftar nilai tertinggi dan nilai terendah, dan nilai rata-rata.

Tabel 4. Data Nilai Tertinggi, Nilai Terendah, dan Nilai Rata-rata Keaktifan hari pertama dan hari ketiga

\begin{tabular}{ccccc}
\hline & \multicolumn{2}{c}{ Hari Pertama } & \multicolumn{2}{c}{ Hari Ketiga } \\
\cline { 2 - 5 } & Kelompok & Kelompok & Kelompok & Kelompok \\
& Kontrol & Eksperimen & Kontrol & Eksperimen \\
Nilai Tertinggi & 80 & 80 & 85 & 90 \\
Nilai Terendah & 40 & 45 & 55 & 70 \\
Nilai Rata-rata & 64 & 63 & 70 & 75,5 \\
Kategori & C & C & B & B \\
Keterangan & Cukup & Cukup & Baik & Baik \\
\hline
\end{tabular}

Sumber: Penelitian 2019 
Berdasarkan hasil pengamatan dan penilaian keaktifan siswa dalam pembelajaran menggunakan model pembelajaran model Quantum Teaching menunjukkan bahwa sebagian besar keaktifan siswa hari pertama pada kelas kontrol dan eksperimen berada kategori cukup denganrata-rata nilai keaktifan kelas kontrol 64 sedangkan kelas eksperimen 63 dan pada hari ketiga pada kelas kontrol dan kelas eksperimen berada ketegori baik dengan rata-rata nilai keaktifan kelas kontrol 70 dan kelas eksperimen 75,5. Gambaran mengenai keaktifan siswa disajikan pada grafik berikut

\begin{tabular}{|c|c|c|c|}
\hline \multicolumn{4}{|l|}{100} \\
\hline \multicolumn{4}{|l|}{90} \\
\hline \multicolumn{4}{|l|}{80} \\
\hline \multicolumn{4}{|l|}{70} \\
\hline 60 & \multicolumn{3}{|c|}{50} \\
\hline \multicolumn{4}{|l|}{40} \\
\hline \multicolumn{4}{|l|}{30} \\
\hline \multicolumn{4}{|l|}{20} \\
\hline \multicolumn{4}{|l|}{10} \\
\hline 0 & $\begin{array}{c}\text { Nilai tertinggi } \\
\text { kelas kontrol } \\
\text { dan eksperimen }\end{array}$ & $\begin{array}{l}\text { Nilai terendah } \\
\text { kelas kontrol } \\
\text { dan eksperimen }\end{array}$ & $\begin{array}{c}\text { Nilai rata-rata } \\
\text { kelas kontrol } \\
\text { dan eksperimen }\end{array}$ \\
\hline H1 kelas kontrol & 80 & 40 & 64 \\
\hline $\mathrm{H} 2$ kelas kontrol & 80 & 45 & 63 \\
\hline H1 kelas eksperimen & 85 & 55 & 70 \\
\hline H2 kelas eksperimen & 90 & 70 & 75.5 \\
\hline
\end{tabular}

Gambar 2. Diagram Keaktifan Peserta didik

Berdasarkan data diatas didapatakan rata-rata nilai keaktifan siswa kelas eksperimen H1 (sebelum perlakuan ) 63 dengan kategori C (Cukup) dan rata-rata nilai keaktifan siswa kelas eksperimen $\mathrm{H} 2$ (sesudah perlakuan) sebesar 73 dengan kategori B (Baik), sedangkan rata-rata nilai keaktifan siswa kelas kontrol yang menggunakan model pembelajaran konvensional H1 sebesar 64 dengan kategori C (cukup) dan H2 mendapatkan 70 dengan kategori B(Baik), keaktifan siswa dikatakan tuntas apabila mencapai kategori B (Majid.2014:150).

maka dapat diambil kesimpulan bahwa pembelajaran Quantum Teaching memberikan perbedaan yang signifikan atau dampak yang efektif terhadap prestasi belajar siswa dan keaktifan siswa dalam kegiatan belajar mengajar.

Pada penelitian ini, pembelajaran dengan model Quantum Teaching merupakan pengajaran yang berdaya guna lebih dengan orkestrasi bermacam-macam interaksi yang ada didalam dan disekitar momen belajar.

Setelah dilakukan analisis data dari awal penelitian sampai akhir penelitian dpat disimpulkan bahwa strategi pembelajaran menggunakan model Quantum Teaching efektif terhadap hasil belajar dan keaktifan siswa kelas V SDN 02 Bedagas. Dengan demikian, tujuan penelitian telah tercapai dan peneliti membuktikan dengan peningkatan hasil belajar IPS 88,89\% mencapai KKM denan nilai pretest 68,89 menjadi 83,61 pada posttest sehingga nampak selisih14,72.

Penelitian ini juga dapat menunjukan jika sesuai dengan teori kontruktivisme. Strategi pembelajaran yang digunkan sesuai dengan penjabaran teori kontruktivisme. Peserta didik berperan katif membangun sendiri pengetahuannya, mencari arti dari apa yang mereka pelajari dan merupakan proses menyelesaikan konsep dan ide-ide baru dengan kerangka berfikir yang telah ada dan dimilikinya.

\section{Simpulan dan Saran}

Berdasarkan hasil penelitian yang telah dilaksanakan dapat disimpulkan bahwa strategi pembelajaran menggunakan model Quantum Teaching efektif terhadap keaktifan dan prestasi belajar siswa kelas V SDN 02 Bedagas pada materi proklamasi kemerdekaan indonesia. Dibuktikan dengan mengunakan uji-t diperoleh hasil $t_{\text {hitung }}=3,132$ dan koefisien tersebut signifikan pada taraf $5 \% \mathrm{dab} d \mathrm{~b}=$ 33 maka diperoleh $t_{\text {tabel }}=2,021$ jadi nilai $t_{\text {hitung }}>t_{\text {tabel. }}$ dan meningkatnya jumlah siswa yang tuntas adalah 11 untuk kelas kontrol ,dari 17 siswa yang mengikuti tes dengan nilai rata-rata 75,88 sedangkan untuk kelas 
eksperimen sebanyak 16 siswa yang yang tuntas dengan nilai rata-rata 83,61. Melalui presentase jumlah siswa yang tuntas adalah $64,71 \%$ dari kelompok kontrol dan kelompok eksperimen sebesar $88,89 \%$ hal ini menunjukan bahwa strategi menggunakan model Quantum Teaching lebih efektif dari pada pembelajaran yang tidak menggunakan model pembelajaran Quantum Teaching (konvensional) pada materi proklamasi kemerdekaan indonesia kelas V SDN 02 Bedagas. Keaktifan belajar siswa dapat disimpulkan bahwa keaktifan belajar siswa baik. Ketercapaian keaktifan siswa pada kelas kontrol 67,96 dan dikategorikan baik sedangkan untuk ketercapaian kelas eksperimen 75,5 dan dikategorikan baik. Berdasarkan hasil penelitian yang telah dilakasanakan dapat disimpulkan bahwa strategi pembelajaran menggunakan model Quantum Teaching efektif terhadap keaktifan dan prestasi belajar siswa kela V SDN 02 Bedagas pada materi proklamasi kemerdekaan indonesia

\section{Daftar Rujukan}

Ahmadi, A. dkk. 2004. Psikologi belajar. Jakarta: PT. Asdi Mahasatya

Alma, B. dkk. 2003. Hakekat studi sosial (the nature of social studies). Bandung: Alfabeta

Arifin, Z. 2013. Evaluasi Pembelajaran. Bandung: PT. Remaja Rosdakarya

Arikunto, S. 2013. Dasar-dasar evaluasi pendidikan. Jakarta: Bumi Aksara

Bahadin. 2014. An Investivigation the Effect of Quantum Learning Approach on Attitude. Turkey. Education Research Assosiation The International Journal of Research in Teacher Education. ISSN: 1308-951IX | Vol. 5. No. 2, Hal. 61-72. Tersedia: https://ijrte.eab.org.tr. Diakses : 25 Agustus 2018

Creswell 2014. Research Design. Yogyakarta: Pustaka Pelajar

Depdiknas. 2003. Undang-Undang No.20 tahun 2003 tentang Sistem Pendidikan Nasional. Jakarta: Depdiknas.

Deporter, B. 2010.Quantum Teaching. Bndung: Mizan Pustaka

Dimyati, dkk. 2009. Belajar dan Pembelajaran. Jakarta: Rineka Cipta

Gunarhadi. 2014. The Impact of Quantum Teaching Strategy on Student Academic Achievements and SelfEsteem in Inclusive Schools. Malaysian Journal of Learning and Instruction.2014 | Vol. 11 Hal. 191205. Tersedia: https://eric.edgov/?id=EJ1137291. Diakses: 25 Agustus 2018

Huda, dkk. 2013. Pengaruhmodel Pembelajaran Quantum dalam Pembelajaran IPA terhadap Motivasi belajar dan Penguasaan Konsep Siswa Kelas IV SDN 03 Pancor. 2013 | Vol. 3. Tersedia: https://ejournal.undiksha.ac.id/ Diakses: 25 Agustus 2018

Permendiknas. 2006. Permendiknas Nasional Republik Indonesia No.22 tahun 2006 tentang Standar Isi untuk SSatuan Pendidikan Dasar Menengah. Jakarta: permendiknas

Sadirman. 2011. Interaksi dan Motivasi Belajar Mengajar. Jakarta: Raja Grafindo Persada

Sagala, S. 2012. Konsep dan Makna Pembelajaran. Bandung: Alfabeta

Sapriya, dkk. 2008. Konsep Dasar Ips di SD. Jakarta: Bndung UPI Press

Sadjiyo, dkk. 2012. Pendidikan IPS di SD. Tangerang Selatan: Universitas Terbuka

Shoimin Aris.2014. 68 Model Pembelajaran Inovatif dalam Kurikulum 2013. AR-Ruzz Media. Yogyakarta

Sudjana, N. 2013.Penilaian Hasil Proses Belajar Mengajar. Bandung: Rosdakarya

Sugiyono. 2015. Metode Penelitian Pendidikan (pendekatan Kuantitatif, Kualitatif, dan R\&D). Bandung: Alfabeta 
Susanto, A. 2014. Teori Belajar dan Pembelajaran di Sekolah Dasar. Jakarta: Prenadamedia Group

Syah, M. 2011. Psikologi Pendidikan dengan Pendekatan Baru. Bandung: PT Remaja Rosdakarya

Taheri, M. et.all 2015. Strategies to Improve Students' Educational Achievement Motivation at Guilan University of Medical Sciences. Res Dev Media Educational. Doi: 10.1517/rdme.2015.024 | Page: 133-139. Tersedia: http://scholar.google.com/scholar 11/2/2019. Diakses: 01 Februari 2019

Trianto. 2013. Mendesain model pembelajaran inovatif-progresif: Konsep, Landasan dan Implementasinya pada Kurikulum Tingkat Satuan Pendidikan ( KTSP). Jakarta: Kencana Prenada Media Group

Wahab, A. 2009. Metode dan Model-model Mengajar IPS. Bandung: Alfabeta

Yamin, M. 2012. Desain Baru Pembelajaran Konstruktivistik. Jakarta: Referensi

Yahya, Husniyati . 2017. Pengaruh Penerapan Model Pembelajaran Quantum Teaching Terhadap Hasil Belajar Biologi Siswa Sms Islam Terpadu Al-Fityan Gowa . Jurnal Biotek Volume 5 Nomor 1 Juni 2017 